\title{
BLOQUEADO, SUSPENSO, FORA DO AR: A ATUALIDADE DA CENSURA NO ESPAÇO DIGITAL ${ }^{1}$
}

\author{
CARLA BARBOSA MOREIRA*
}

\begin{abstract}
RESUMO: Desde o período da Ditadura Civil-Militar no Brasil, quando as condições de cerceamento da liberdade de usar a palavra foram institucionalizadas, não se fala tanto em censura como nos últimos anos. Este é o objeto de análise deste texto - a censura -, que pode ser compreendida como um mecanismo político e ideológico que intervém na ordem do discurso, visando o controle de sentidos, seja pelo silenciamento, seja pelo evidenciamento (Moreira, 2007). A partir dessa noção e à luz da Análise do Discurso de vertente francesa e seus desdobramentos no Brasil (Pêcheux, 1988[1975]; Orlandi, 2004[1996]), a censura foi analisada em sua materialidade digital, admitindo-se as implicações que as relações entre sujeito, conhecimento e tecnologia trazem para a compreensão dos processos de significação e para a memória. Desse modo, as políticas que produzem (novas/outras) técnicas e saberes censórios no espaço digital foram analisadas enquanto condições de produção do discurso no Facebook. Essas condições de produção, em sentido estrito, e as condições de produção históricas e sociais - que apontam implicações para a relação linguagem e tecnologia - permitem-nos compreender um processo de constituição do sujeito - referido pelo Facebook por "você", "usuário" e "pessoa" - e efeitos de sentido para censura. Assim, a análise do que vem sendo compreendido como censura no/pelo Facebook confirmou novos gestos materializados por discursividades como "remover", "desabilitação", nas condições de produção dispostas nos Termos e princípios do Facebook, e marcas como "bloquear", "suspender", "tirar do ar", “exilar", "impedir", "calar", um “conteúdo", um "perfil”, "página", "marca X", "ele". O resultado desta análise sobre a censura indica, ainda, um campo aberto de investigação acerca das práticas censórias reconfiguradas para/na materialidade digital em decorrência das mudanças nas relações sociais.
\end{abstract}

Palavras-chave: Discurso, Censura, Facebook

RÉSUMÉ: Depuis la période de la Dictature Civile-Militaire au Brésil, moment où les conditions de restriction de la liberté de parole ont été institutionnalisées, on n'a pas parlé autant de censure comme dans les dernières années. Voilà l'objet d'analyse de ce texte - la censure -, qui peut être comprise comme um mécanisme politique et idéologique qui intervient dans l'ordre du discours, visant le contrôle de sens, soit par le silenciement soit par la mise en évidence (Moreira, 2007). À partir de cette notion et sous la lumière de l'Analyse du Discours française et son développement au Brésil (Pêcheux, 1988[1975]; Orlandi, 2004[1996]), la censure a été analysée par sa matérialité digitale, en considérant que les politiques du Facebook produisent (de nouvelles/d'autres) techniques et des savoirs censoriaux et fonctionnent comme conditions de production du discours dans ce réseau social. Ces conditions de production, au sens strict, et les conditions de production historiques et sociales - qui impliquent la relation langage et technologie - permettent nous de comprendre un processus de constitution du sujet - référé par le Facebook comme "vous », « utilisateur » et " personne » - et des effets de

\footnotetext{
${ }^{1}$ Agradeço pelo apoio financeiro, concedido pelo CNPq e pelo CEFET-MG.

* Centro Federal de Educação Tecnológica de Minas Gerais (CEFET-MG), Belo Horizonte, MG, Brasil.profcarlabmor@gmail.com.
} 
sens pour la censure. Ainsi, l'analyse de ce qui est dernièrement compris comme censure par/dans le Facebook confirme de nouveaux gestes matérialisés par des discoursivités comme " supprimer », " désactivation ", dans les conditions de production disposées dans les Conditions et principes du Facebook, et des marques comme " bloquer », " suspendre ", " exiler », " empêcher ", " taire ", un « contenu », un " profil », « page », « marque X, « lui ». Le résultat de cette analyse sur la censure indique, encore, un domaine ouvert d'investigation à propos des pratiques censoriales reconfigurées par/dans la matérialité digitale dû aux changements dans les relations sociales.

Mots-clé: Discours, Censure, Facebook

\section{INTRODUÇÃO}

Enquanto houver a possibilidade da palavra ou o espaço do silêncio significante, há de se atentar para a presença, mais ou menos incisiva, da censura. Existe uma grande dificuldade na mobilização deste termo desvinculado de um contexto de regimes autoritários, que historicamente favoreceram sua produção e institucionalização. E há uma grande dificuldade na percepção de políticas e práticas/discursos autoritários em sociedades consideradas democráticas. As consequências disso para o estudo dos processos de significação são imensas e carecem de serem analisadas nas mais diversas áreas, principalmente nos estudos de linguagem.

Inscrita na perspectiva teórica da Análise do Discurso pecheutiana (PÊCHEUX, 1988[1975]) e seus desdobramentos no Brasil, esta análise concebe o discurso enquanto acontecimentos sócio-históricos que envolvem sujeitos em relação e em diferentes posições ideológicas. Compreende-se que esses acontecimentos estão inscritos desde já na relação que Orlandi (2007[1992]) apresenta: estar em silêncio/romper o silêncio ou ficar em silêncio/apropriar-se da palavra é um gesto político. Portanto, está aí colocada a questão da divisão de sentidos, que, nesta visada teórica, impõe uma postura ética no trabalho de interpretação.

Em termos de pesquisa, podemos afirmar que ainda há uma carência de estudos que empenham um tratamento teórico-analítico aos mecanismos de controle (interdição/evidenciamento/arquivamento/circulação, vigilância ou monitoramento) que interferem nos processos discursivos. Desse modo, de um lado, é necessário investigar e retomar ${ }^{2}$ os arquivos de censura para compreender seus modos de produção, as formas de constituição, controle e funcionamento do discurso. De outro, é preciso avançar. Se aceitamos que ainda há muito por ser compreendido sobre as possibilidades e efeitos das novas tecnologias no funcionamento do discurso, estamos diante de um outro espaço de problemas para os estudos da censura.

Na medida em que podem ser concebidos e analisados como gestos políticos, administrativos, jurídicos ou dos próprios sujeitos materializados historicamente

${ }^{2} \mathrm{O}$ livro em que tais questões são apontadas e discutidas está em fase de escrita, com previsão de publicação para 2018. 
no/sobre o discurso do ciberespaço - produzindo técnicas, recursos ${ }^{3}$, novos gestos de escrita e de interpretação -, os mecanismos de controle do discurso na internet apresentam-se como objeto de investigação produtivo para as Teorias do Discurso.

No Brasil, os mecanismos de controle do Estado sobre a mídia impressa ou eletrônica são vários, bem como suas técnicas, que envolvem desde a legislação até a censura policial. A designação de censores e criação de agências reguladoras normalmente ocorrem em períodos de autoritarismo e Ditadura. No Brasil, destacamos a indicação feita por D. João de censores régios na Mesa do Desembargo do Paço, em 1808; a criação do DIP (Departamento de Imprensa e Propaganda, em 1939, na Ditadura Vargas); a criação do Ministério das Comunicações, em 1967, na Ditadura Civil-Militar. Em que pese a similaridade das determinações políticas e ideológicas que produziram práticas, técnicas, justificativas e efeitos diversos na constituição, circulação e controle dos discursos, em especial na mídia impressa, faz-se necessário desnaturalizar as evidências produzidas acerca do espaço digital, entre as quais, a de que trouxe aos seus usuários a possibilidade de exercer livremente um direito constitucional: manifestar seus pensamentos, divulgar ideias, organizar-se socialmente, promover engajamento político.

Desse modo, do ponto de vista histórico, está delineado um cenário propício para a produção de diferentes formas de controle. Ora, justamente por essa suposta liberdade, mas sem dúvida pela efetiva ampliação da participação das diversas camadas da população na vida social e política do Brasil que, após a ditadura, é a sociedade em rede, a sociedade de mercado, a que mais tenta instituir mecanismos de controle e vigilância, não só à mídia e às empresas, mas aos sujeitos. Esses mecanismos têm sido produzidos, propostos, aplicados, de diversas formas e mais intensamente em virtude do atual cenário político do Brasil, construído, inclusive, pelos imaginários materializados nos discursos das mídias tradicionais e das mídias sociais.

A questão se torna extremamente problemática na medida em que vivenciamos um momento de crise política e de intensa exposição midiática de um cenário - e de políticos, gestores, juristas - que apresenta as rachaduras de um Estado democrático de Direito, o que gerou várias tentativas de institucionalização de técnicas de controle dos discursos na rede $^{4}$. Nestes termos, é necessário assumir que a base da tríade sujeito, língua e Estado são as relações de poder.

${ }^{3}$ Cf. Orlandi (2003). Em sua visada, é preciso "pensar os 'recursos' do ponto de vista das ciências humanas - reintroduzindo a materialidade histórica, a ideologia e os sujeitos sociais - e sem separar estritamente as instâncias (ciência, tecnologia, administração) em que a mesma palavra 'recurso' produz diferentes efeitos de sentidos. Basta pensar o que é recurso em ciência, em tecnologia, em administração" (ORLANDI, 2003, p. 6), nesse discurso, de "um sujeito não só usuário, mas histórico, social e politicamente significado, produtor de sua existência” (ORLANDI, 2003, p. 5).

4 Pode-se citar, entre outros, o Projeto experimental CTRL + X, organizado pela ABRAJI (Associação Brasileira de Jornalismo Investigativo) com a ajuda de empresas de mídia e tecnologia que costumam ser alvos de processos em que se requer supressão de informações. Segundo o Portal, foram registradas 1663 ações eleitorais na justiça lutando contra a divulgação de informações, sendo que os principais solicitantes são políticos (ABRAJI). O que podem estar querendo evitar é o que Thompson 
De um lado, o fato de os mecanismos de controle - enquanto práticas censórias - serem exercidos de forma incisiva e institucionalizada em período ditadura não pressupõe que estejamos imunes a eles. Nas atuais condições de produção do discurso no ciberespaço, não podemos afirmar que se tratem dos mesmos mecanismos, posto, inclusive, que as relações sociais e de poder não são as mesmas. Assim, a censura pode ser compreendida, de forma mais ampla, pelo/ no modo como atuam os mecanismos de intervenção - seja pela lei, por regras, em função de discursos (da moral, da ética, da religião, etc.), seja pela técnica, pelos recursos tecnológicos, institucionalizados ou não - exercendo algum controle sobre os processos de produção, funcionamento e circulação das diferentes materialidades significantes.

\section{PERSPECTIVA TEÓRICO-METODOLÓGICA}

\subsection{Análise do Discurso e a relação entre linguagem e tecnologia}

A partir do conceito de discurso definido anteriormente, é deslocada a ilusão de que há uma relação direta entre a constituição da língua e da realidade, pois nas línguas se inscreve uma política de sentidos que coloca em cena a divisão de sentidos e a questão de que o sujeito é dividido pelo inconsciente e interpelado pela ideologia. Nesse sentido, discursivamente, o sujeito não se equivale ao indivíduo (uno, indivisível), ou seja, o sujeito é interpelado pela ideologia e conduzido a ocupar um lugar social historicamente determinado. É na relação da tríade sujeito, língua e Estado que aquele significa e resiste. Assim, para além da compreensão do modo de constituição dos sentidos, para esta perspectiva teórica, importa compreender a constituição do sujeito do/no discurso.

Enquanto teoria materialista dos processos discursivos, a Análise do Discurso procura compreender como, na história, foram inscritos efeitos linguísticos materiais, a fim de trabalhar sua discursividade (PÊCHEUX, 1988 [1975]), ou seja, a compreensão do texto enquanto objeto histórico. Desse modo, a teoria se concentra na determinação histórica dos processos de significação, pois é no discurso que as práticas sócio-históricas são materializadas na linguagem, uma vez que ele dispõe de formas de apropriação, pelo indivíduo falante, do universo da língua (ORLANDI, 2004[1996]). Isso significa dizer que a língua é vinculada à história, e a história intervém na língua de forma constitutiva. Como disciplina de interpretação, importa também à Análise do Discurso compreender esse modo de significar.

Para Orlandi (2004[1996]), a língua é o lugar material em que se realizam os efeitos de sentido, ou seja, a língua é a materialidade específica do discurso, e o discurso é a materialidade específica da ideologia (PÊCHEUX, 1988[1975]),

(2005) considerou como um novo tipo de visibilidade. Com a tecnologia midiática, não se trata apenas de tornar muitas pessoas visíveis para poucos, mas permitir que algumas pessoas - principalmente aquelas que exercem o poder - sejam visíveis para muitos. Assim, o poder, afetado pelo (outro) poder, procura resistir à liberdade de expressão, à circulação livre das informações. 
colocando em cena não apenas uma relação material entre língua e ideologia, mas ainda entre inconsciente e ideologia, pois esses dois últimos estão materialmente ligados. A ideologia é aqui entendida não como uma máscara ou ocultação de sentidos, mas como uma prática que inscreve os efeitos de sentido de forma a produzir evidências, naturalizando um determinado sentido como óbvio (MARIANI, 2003).

Em face ao funcionamento do discurso, nestes termos, assume-se que o sentido sempre pode ser outro, em busca de efetivar a ética no trabalho de interpretação. Não se trata assim de considerar todos os sentidos possíveis ou uma oposição entre realidade e imaginário, mas que este é justamente constitutivo daquela. Assim, a materialização dos processos históricos e sociais no discurso pelo sujeito é o próprio imaginário mediador para que ele construa a sua identidade.

Posta a relação de implicação entre memória e ideologia, é preciso ressaltar que há diferentes formas de memória - memória discursiva, memória de arquivo, memória metálica (ORLANDI, 2013) -, que acarretam diferenças no circuito constituição/formulação, armazenamento e circulação dos discursos. Para explicar os gestos de interpretação, é preciso descrever a relação sujeito e memória. Retomando um estudo sobre censura, memória e arquivo (Moreira, 2010), no qual se analisou a formação de saberes e práticas censórias a partir das motivações de arquivos de censura, é possível afirmar que a memória não é linear, mas funciona em dispersão. Ainda que em diferentes períodos e lugares, há um espaço de memória onde os sentidos vão se regularizando. A problemática em questão seria então se interrogar sobre o modo como a memória em dispersão se regulariza com discursos sob controle. A que rede de memória esses sentidos se filiam?

Com Moreira (2009), compreendemos que, mediante uma memória não formulada pelo processo histórico de constituição de sentidos, pela historicidade, faz-se necessário buscar analisar os saberes e as práticas de controle produzidas em suas condições especiais de produção, pois eles têm relação com a própria memória que o constitui; não são saberes externos ou excludentes da relação sujeito, língua e história. Isso significa, ao mesmo tempo, que qualquer gesto, recurso e técnica de controle de arquivos têm relação com a própria memória que o constitui (Moreira, 2010).

Quando se refere às ideologias, Pêcheux (1988 [1975], p. 144) esclarece que elas “não são feitas de 'ideias', mas de práticas, quer dizer, mecanismos que são ligados aos rituais que nos organizam, vinculados ao aparelho político-jurídico e ideológico"; a ideologia não é, nessa concepção, X, mas o mecanismo de produzir X. Desse modo, um ponto fulcral para a problematização formulada para este trabalho é que se tome o meio material na perspectiva da Análise do Discurso: pensar o dispositivo, a técnica e o espaço de dizer em sua materialidade. Em síntese:

São as condições sócio-históricas de produção dos sentidos que determinam e formulam os próprios dispositivos técnicos [...]. Para a Análise do discurso digital esses três patamares são igualmente importantes e constituem o meio material, no qual está implicado, em nosso procedimento analítico, o momento da circulação dos discursos (DIAS, 2016, p. 169). 
Ancoram-se teoricamente neste ponto todos os questionamentos e objetivos acerca de uma investigação dos "mecanismos", "técnicas" e "recursos" de controle dos discursos na internet. Contudo, também o controle assume uma visada discursiva. As condições político-ideológicas do funcionamento do discurso em suas diferentes formas de materialização sempre deveriam nos levar a interrogar, quanto aos processos discursivos, como as formas de poder são produzidas com mecanismos de regulação (repetição, evidenciamento ${ }^{5}$, silenciamento, apagamento, etc.) e resistência (Moreira, 2009).

O silêncio ${ }^{6}$ é uma categoria fundante da linguagem (ORLANDI, 2007[1992]), mas não se confunde com ela, pois a matéria significante do silêncio - e suas dimensões - implica diferentes instrumentos de análise. Assim, em pesquisas sobre a produção e funcionamento do silêncio local - a censura - no discurso jornalístico e em contextos políticos autoritários, Moreira $(2009 ; 2010)$ privilegiou três eixos de análise: produção de saberes e práticas censórias no discurso jornalístico, funcionamento do discurso sob censura e a gestão das línguas (políticas linguísticas e de ensino) enquanto formas de silenciamento, de evidenciamento e de promoção das línguas. Compreendemos que os mecanismos discursivos de controle e de resistência representam as lutas - os embates na história - materializadas no discurso; a divisão dos sentidos.

O discurso que vem sendo naturalizado acerca do acesso e da liberdade de expressão nas redes sociais, ao mesmo tempo que aponta para uma reconfiguração dos espaços de dizer, apaga as relações de poder, a disputa pelos sentidos, opacizadas pela ilusão de que a participação de todos e de qualquer um reproduz um espaço democrático em que todos os sentidos seriam possíveis. Comecemos, portanto, na tentativa de desfazimento dessa ilusão, a discutir as condições de produção do discurso e as políticas do Facebook.

\subsection{Políticas do dizer e controle: uma abordagem às condições de produção do discurso no Facebook}

Retomando Foucault (1999a), na sociedade disciplinar, os mecanismos de controle se distribuem em todas as instâncias e preveem certas formas de exercício da vigilância. Em outro mecanismo, é preciso regulamentar e punir. Assim funcionou a censura no período da Ditadura Civil-Militar no Brasil, enquanto mecanismo institucionalizado a partir do AI-5, repressor, atingindo o ápice do aparelho de coação - atingindo o homem desde a escola -, com suas normas censórias (Moreira, 2009), bilhetinhos e telefonemas, com a presença dos censores nas redações, nos teatros; com as penalidades - desde matérias censuradas a

${ }^{5}$ Moreira (2009) analisou o evidenciamento enquanto técnica de controle, afirmando que tão significativo quanto proibir e apagar, é evidenciar. Estados em que a censura é institucionalizada e se impõe como meio de controle dos sentidos pretendem justamente controlar os sentidos da memória; assim precisam também - evidenciando-os - naturalizá-los.

${ }^{6}$ Cf. em Orlandi (2007[1992]) as categorizações do silêncio. A autora formula ainda as dimensões da relação entre censura e interdição. De um lado, está o impossível, o historicamente nãodizível. Do outro lado da dimensão da interdição está a censura local, um traço do formulável, porém proibido em certas condições. 
edições inteiras recolhidas, incluindo o fechamento de jornais. Não funcionavam, contudo, isoladamente:

Por outro lado, esses dois conjuntos de mecanismos, um disciplinar, o outro regulamentador, não estão no mesmo nível. Isso lhes permite, precisamente, não se excluírem e poderem articular-se um com o outro. Pode-se mesmo dizer que, na maioria dos casos, os mecanismos disciplinares de poder e os mecanismos regulamentadores de poder, os mecanismos disciplinares do corpo e os mecanismos regulamentadores da população, são articulados um com o outro. (FOUCAULT, 1999b, p. 299).

A despeito do modo como o sistema do poder procurou - e ainda procura produzir corpos disciplinados, Foucault (2006, p. 66) afirma que é "preciso um sistema de coações, de coerção e de punição". Contudo, avançou no sentido de constatar o abrandamento das instituições, mas a manutenção de funções. Reforçou (FOUCAULT, 2006, p. 67) que hoje, "as pessoas não são mais enquadradas pela miséria, mas pelo consumo". Não se trata somente de proibir, mas de incitar. Deleuze (1993) vai retomar esse movimento teórico de Foucault ao apontar não apenas a incitação, mas marca que mais "produtivo" que proibir e reprimir, é administrar. Não é uma substituição, ressaltamos. Quando trazemos a questão para ser problematizada no escopo da relação linguagem e tecnologia, o controle pode ser compreendido enquanto mecanismo que funciona de outro modo:

[...] ainda que os mecanismos disciplinares e do biopoder estejam ativos, o exercício do poder ocorre de maneira mais incisiva pela via do controle que imprime as táticas, estratégias e que constitui os saberes de nossa época. A partir dessa perspectiva, a captura de informações realizada pelo mercado libertou-se do indivíduo e das fronteiras, e apenas joga com esses velhos limites. Joga, por exemplo, ao reativar a figura individual que concorda com termos de acesso, de serviço e de privacidade, ao reafirmar essa figura do direito que pouco lhe interessa, ao estimular a constituição identitária e a figura egóica das redes sociais, ao mesmo tempo em que opera a diluição do indivíduo e da identidade, para extração de valor, para troca de informações que são apenas fragmentos de desejos ou aspirações, pura subjetividade, virtualidade, potencialidade (KANASCHIRO, 2016, p. 22).

De acordo com Kanashiro (2016), no que tange às questões referentes à atualidade da sociedade da informação, da sociedade da vigilância, da sociedade do controle, entre outros, não se restringe ao Estado a capacidade de coletar dados, arquivar, monitorar, identificar, etc.: "Redes sociais como Facebook, [...] têm uma capacidade de coleta de informações que atravessa uma dimensão da vida não capturada pelos mecanismos de Estado durante a era industrial" (KANASHIRO, 2016, p. 21).

Este aspecto apontado é basilar quando tomamos como objeto de análise a censura na atualidade, e mais especificamente o modo como o/no Facebook podem ser compreendidos os mecanismos de controle, bem como os efeitos de sentidos de "censura" aí instituídos. Essa compreensão parte das condições de produção do discurso que, para a Análise do Discurso, referem-se ao contexto imediato e ao contexto ideológico e sócio-histórico que determinam a reunião de certos tipos de textos a partir de certas restrições consideradas estáveis. Assim, as palavras e a produção dos discursos estão vinculadas a certas redes 
de significância (ORLANDI, 2003[1999]). Tomamos, enquanto gesto analítico, tanto as determinações históricas e sociais que se inscrevem na relação linguagem e tecnologia, e se materializam, em uma perspectiva discursiva, no próprio discurso do Facebook, quanto as determinações imediatas de produção, controle e circulação do discurso no Facebook, que se configurou, para esta pesquisa, como restrições que carecem de análise.

Nos “Termos e Políticas do Facebook” há uma autodefinição e apresentação de outras definições importantes para compreendermos as principais condições de produção ${ }^{7}$ para a produção, funcionamento e circulação dos discursos nessa rede social. Assim definem os termos "Facebook" ou "Serviços do Facebook":

\begin{abstract}
abrangem os recursos e serviços que disponibilizamos, inclusive através de (a) nosso site www.Facebook.com e qualquer outro site da marca Facebook ou sites de marca compartilhada (incluindo subdomínios, versões internacionais, widgets e versões para celular); (b) nossa Plataforma; (c) plug-ins sociais, como o botão Curtir, o botão Compartilhar e outras ofertas similares (d) e outras mídias, marcas, produtos, serviços, softwares (como uma barra de ferramentas), dispositivos ou redes já existentes ou desenvolvidos posteriormente (Termos e Políticas do Facebook $^{8}$ ).
\end{abstract}

Os Termos e Políticas do Facebook ${ }^{9}$ incluem a Declaração dos Direitos e Responsabilidades - "os termos que você concorda quando usa o Facebook" "baseada nos Princípios do Facebook" $"$. Nos TPF, através de uma linguagem objetiva, o leitor é referido por "você", e identificado, através da marca de definição isto é (Moreira, 2009), por seu "nome e foto do perfil":

\title{
CP1: Quem é "você"
}

Quando você publica conteúdos ou informações usando a opção Público, você está permitindo que todos, incluindo pessoas fora do Facebook, acessem e usem essas informações e as associem a você (isto é, ao seu nome e foto do perfil ${ }^{11}$ ). (TPF, item 4).

O termo "conteúdo" envolve tudo que você ou outros usuários publicam, fornecem ou compartilham usando os Serviços do Facebook. (TPF, item 3)

"Plataforma”, envolve um "conjunto de APIs e serviços (como conteúdo) que permitem que outras pessoas, inclusive desenvolvedores de aplicativos e operadores de sites, recuperem dados do Facebook ou forneçam dados para nós (TPF, item1).

${ }^{7}$ Doravante $\mathrm{CP}$, para se referir à discussão das condições de produção imediatas.

${ }^{8}$ Disponível em: $<$ https://pt-br.facebook.com/policies $>$. Acesso em: 05 maio 2017.

${ }^{9}$ Doravante TPF.

${ }^{10}$ Disponível em: $<$ https://www.facebook.com/principles.php $>$. Acesso em: 05 maio 2017.

${ }^{11} \mathrm{O}$ uso do itálico, conjugado com o negrito, serve para destacar o que queremos dar ênfase nos recortes e pode ser compreendido como marca/materialização, na língua, dos aspectos sócio-históricos e ideológicos a serem discutidos na análise. 
Desse modo, uma vez que se cria um perfil, com nome e foto, concorda-se com os TPF para uso dos recursos e serviços, que são disponibilizados, ainda, com base em regras de conduta e funcionamento dos serviços no/do Facebook. Constitui-se, assim, um "usuário", referido por "você" que passa a possuir "direitos" e que deve se submeter a regras, responsabilidades e princípios que regem essa rede social. É ainda uma "pessoa" que autoriza que (seus) dados sejam fornecidos ou destinados a outras "pessoas" como "desenvolvedores de aplicativos e operadores de sites", além de "nós", o Facebook (TPF, item1).

\section{CP2 - A propriedade e o controle do dizer}

O Facebook informa a Política de Privacidade e dispõe que, ao compartilhar as "suas" informações e conteúdos, "você" concorda com a Declaração de Direitos e Responsabilidades ${ }^{12}$, constante dos TPF. Assume, com a "concessão" do "usuário", o direito de licença e de uso do que se diz. Portanto, pode-se dizer que o Facebook se torna, juntamente com o usuário, proprietário do dizer.

Você é proprietário de todas as informações e conteúdos que publica no Facebook e pode controlar o modo como serão compartilhados por meio de suas configurações de privacidade e de aplicativos. (Declaração de Direitos e Responsabilidades, $\mathrm{TPF}^{13}$ )

Para conteúdos protegidos por leis de direitos de propriedade intelectual, como fotos e vídeos (conteúdo IP), você nos concede especificamente a seguinte permissão, sujeita às suas configurações de privacidade e de aplicativos: você nos concede uma licença global não exclusiva, transferível, sublicenciável, livre de royalties para usar qualquer conteúdo IP publicado por você ou associado ao Facebook (Licença IP). (Declaração de Direitos e Responsabilidades, TPF, item 1)

Quando você publica conteúdos ou informações usando a opção Público, você está permitindo que todos, incluindo pessoas fora do Facebook, acessem e usem essas informações e as associem a você (isto é, ao seu nome e foto do perfil). (Declaração de Direitos e Responsabilidades, TPF, item 4)

Compreendemos, a partir da CP2, que o "usuário", ao criar um perfil no Facebook, automaticamente concorda em seguir regras sobre como usá-lo e sobre como ele pode coletar/usar suas informações e o que/conteúdo "você" diz: "você" concorda em respeitar o modo "como você pode usar o Facebook ("usando a opção", "por meio de") para compartilhar com outros e como coletamos e podemos usar seu conteúdo e informações". Assim, informa que há uma política de propriedade e de uso das informações e conteúdos, e que passa a ter o direito

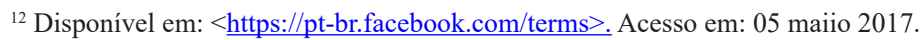

13 Segundo o Facebook, também referenciado por "Declaração", "Termos" ou "DDR". Disponível em $<$ https://pt-br.facebook.com/terms $>$. A Declaração de Direitos e Responsabilidades que expõem os provedores de conteúdo na rede segue o disposto no Marco Civil da Internet, Lei 12.965/2014, MCI. 
sobre eles, adquirindo uma licença de propriedade até a "remoção" do conteúdo e conta, ou seja, até que ocorra o apagamento do conteúdo e da conta do "usuário" ou "pessoa". Informa, ainda, que o apagamento pode não ser eficaz se o conteúdo foi compartilhado, mas não "excluído" por outras pessoas.

\section{CP3 - O que pode o que não pode ser dito}

É importante recuperar o histórico da institucionalização da censura no que diz respeito justamente à segurança. As justificações para as regulações e proibições estão pautadas na Lei de Segurança Nacional, a doutrina da Escola Superior de Guerra (ESG). Na Declaração de Direitos e Responsabilidades, o item 3 é destinado à segurança. O Facebook afirma não poder garantir a segurança e que precisa da ajuda dos "usuários" que estão comprometidos com uma lista que se configura como proibições a eles mesmos. Sobre os conteúdos, podem ser destacadas as seguintes proibições.

- Você não irá intimidar, assediar ou praticar bullying contra qualquer usuário.

- Você não publicará conteúdos que contenham discurso de ódio, sejam ameaçadores ou pornográficos; incitem violência; ou contenham nudez ou violência gratuita ou gráfica.

- Você não irá desenvolver nem operar um aplicativo de terceiros com conteúdos relacionados a álcool, encontros ou outro conteúdo adulto (incluindo anúncios) sem as restrições apropriadas com base em idade.

- Você não publicará conteúdo ou praticará qualquer ato no Facebook que infrinja ou viole os direitos de terceiros ou a lei.

- Nós podemos remover qualquer conteúdo ou informação publicada por você no Facebook se julgarmos que isso viola esta declaração ou nossas políticas.

- Você não deve publicar documentos de identificação ou informações financeiras confidenciais de terceiros no Facebook. (Declaração de Direitos e Responsabilidades, TPF, item 3 e 4)

- Removeremos conteúdos, desabilitaremos contas e poderemos trabalhar com as autoridade locais se acreditarmos que há um risco real de danos físicos ou ameaça direta à segurança pública. Saiba mais sobre como o Facebook lida com conteúdos abusivos (TPF, Padrões da Comunidade). ${ }^{14}$

Por uma lista de proibições, expressas com verbos no futuro, o Facebook busca controlar as práticas discursivas de seus "usuários". Importante perceber que, no discurso mesmo da proibição ("você não" pode), o Facebook se autoriza à "remoção", à "desabilitação" ("nós podemos") de conteúdos e informações "abusivos" pela Declaração e suas Políticas como justificação 2017.

${ }_{14}$ Disponível em: <https://pt-br.facebook.com/communitystandards $>$. Acesso em: 05 maio 
para garantia da segurança. Os conteúdos abusivos dizem respeito às "ameaças diretas, autoflagelação, organizações perigosas, bullying e assédio, ataques a figuras públicas, atividades criminosas, exploração e violência sexual, produtos controlados, nudes, discurso de ódio" (TPF, Padrões da Comunidade). Com as análises constantes do item 3 deste texto, veremos que existem razões não expressas na TPF e que elas não são evidenciadas.

Quanto ao uso de mensagens, na Central de Ajuda do Facebook ${ }^{15}$, os termos "bloquear" e "impedido" têm destaque através de perguntas-respostas, que orientam os "usuários" quanto às justificações para a prática que impede o envio ou compartilhamento de mensagens e envio de solicitações de amizade.

- Por que meu envio de mensagens foi bloqueado?

- Por que estou impedido de compartilhar no Facebook?

- Por que não consigo encontrar a publicação que estava procurando? (Central de Ajuda do Facebook).

As justificações referem-se ao modo como o "usuário" usou as mensagens do Facebook, que podem ter sido marcadas como "indesejadas". O Facebook ainda informa que o bloqueio também acontece devido ao alto número de publicações em curto espaço de tempo.

Nas condições aqui colocadas, o processo de produção histórica dos sentidos é substituído, na internet e, mais especificamente, no Facebook, pelo estabelecimento de normas, pela produção de saberes, definições, técnicas, que motivarão esse organismo - o discurso. E é na análise dessa produção que reside também a possibilidade de compreender como a ideologia se manifesta em rede. Se entendemos que a significação é histórica e sua materialidade é a historicidade da palavra, serviços como os que oferecem o Facebook, os provedores de conteúdo, de acesso, de hospedagem, de correio eletrônico, fazem significar - de outro modo - este espaço de dizer e de silenciar, e seu funcionamento - a partir de um agenciamento político, mercadológico, social - reclama sentidos.

Como o sujeito significa nessas relações e como os processos de produção e circulação dos sentidos são compreendidos a partir de uma perspectiva que toma a relação tecnologia e linguagem enquanto condição de significação?

Os estudos já destacados neste trabalho acerca do silenciamento têm grande importância no espaço de formação, organização e constituição do arquivo. No caso dos arquivos destruídos, a memória está apagada; o arquivo, do ponto de vista documental, não pode ser recuperado porque foi destruído. Sabe-se, contudo, que ele constitui todo um domínio de memória, já que deixa marcas nos discursos que circularam (Moreira, 2010, p. 115). E os conteúdos, as informações e dados delatados são possíveis - ou não - de serem recuperados?

15 Disponível em: < https://www.facebook.com/help/986265348145792?helpref=related $>$. Acesso em: 05 maio 2017. 
O espaço digital, fundamentalmente urbano (ORLANDI, 2010) e determinado por uma ordem específica inscrita no funcionamento da "memória metálica", possui, por assim dizer, um modo específico de circulação dos sentidos. Produzida pelas novas tecnologias de linguagem, a memória metálica ou memória da máquina, da circulação, não se constitui pela historicidade, mas por um construto técnico, como o computador (ORLANDI, 2006).

Nas condições de produção atuais e consideradas as particularidades do ciberespaço, cabe ainda se interrogar acerca desses saberes e práticas que produzem uma memória metálica. Em que medida se pode, assim, afirmar que, ao trabalho de interpretação, pressupõe-se um comprometimento, de forma ética, com o outro? Uma afirmação que precisa ser recorrente é a de que o sentido sempre pode ser outro. Interpretar é, assim, um gesto de leitura, é trabalhar a opacidade do texto e explicitar o modo como um objeto simbólico produz sentidos (ORLANDI, 2004[1996]).

A partir do princípio discursivo do trabalho do político, ao levarmos em conta, portanto, o fato de que o sentido é sempre dividido, tendo uma direção que se especifica na história, pelo mecanismo ideológico de sua constituição; há simbolização das relações de força, de poder, que se estabelecem na divisão própria à sociedade capitalista (ORLANDI, 2013). A autora cita Dias (2011) para marcar a particularidade da discursividade do eletrônico como "um processo histórico e ideológico de significação da nossa sociedade contemporânea, do modo como estamos nela, como praticamos os espaços" (DIAS, 2011, p.58).

Essa ponderação é relevante na medida em que, ao apresentarmos questões acerca da informatização e virtualidade da linguagem, precisamos transitar entre os construtos teóricos, trazendo-os para significarem teoricamente no campo do discurso. Assim, a quantidade (e não historicidade); administração (e não o político, instituição); organização (e não ordem, funcionamento), a comunicação (e não relação de sentido), são filiações que fazem parte do modo como a sociedade está significando as novas tecnologias de linguagem (DIAS, 2014).

Para Orlandi (2010), enquanto espaço virtual, que tem sua materialidade e produz efeitos, é preciso considerar o que se repete e se atualiza:

A linguagem digital, ou o discurso eletrônico, como prefiro chamar, re-organiza a vida intelectual, re-distribui os lugares de interpretação, desloca o funcionamento da autoria e a própria concepção de texto. Mas não nos enganemos. É ainda uma tecnologia da escrita. Tem um impacto semelhante ao da invenção da imprensa. Mas difere desta pela sua natureza do ponto de vista técnico, científico e administrativo, em termos sociais e políticos. (ORLANDI, 2009, p. 63).

Do ponto de vista político e social, ao trazer como problemática os mecanismos de controle da/na rede social Facebook, compreendemos que as políticas que agenciam o espaço de dizer e não dizer preveem punição, como "bloqueio", a "remoção", "desabilitação", "impedimento" de informações, conteúdos e perfis. Diferentemente da censura institucionalizada a partir do Ato Institucional $\mathrm{n}^{\circ} .5$, em 13/12/1968, nas relações de poder constantes do Facebook, temos controle, regras e punições agenciadas por uma relação direta, cordial e informal com o "usuário". 
Contudo, compreendemos que, em CP3, o discurso da proibição ("você não" pode; "remoção"; à "desabilitação") funciona de modo similar àquele em que o Estado, através de uma lista de normas censórias enviadas às agências jornalísticas em 18/12/1968 (Moreira, 2009, Anexo I) discursivizou uma prática censória logo após institucionalização da censura. As marcas linguístico-discursivas de negação "não deverão" ser divulgadas e "não publicar" (sd41, sd42, sd44, sd51, sd54, sd55); "é vedado", "é vedado permitir", "é vedado divulgar" ( $s d 49$, sd47), em forma de lista, materializam, no discurso, um modo de controlar o dizer (Moreira, 2009, p.138). Com nossas análises, queremos aqui nos implicar não só com o questionamento feito anteriormente - a que rede de memória esses sentidos se filiam? -, mas nos interrogamos quanto ao domínio de memória ao qual o gesto censório se filia.

Assim, comparecem, no discurso do gesto censório em questão, as sequências parafrásticas que se filiam a um mesmo domínio de memória da lista de normas censórias de 1968. Nesse domínio, portanto, materializam-se não só as negações, mas opera uma ordem do discurso em que o modo de proibir se repete, fazendo a censura significar em um outro discurso, o do Facebook.

\section{A CENSURA DISCURSIVIZADA NO FACEBOOK}

Em termos metodológicos, esta etapa da pesquisa partiu da delimitação do corpus da pesquisa, que abrange o discurso sobre censura na rede social Facebook. Para Análise do Discurso, as condições de produção ou as circunstâncias em que os discursos são produzidos tornam possível sua formulação e sua compreensão (PÊCHEUX, 1988[1975]). Uma vez analisadas anteriormente as condições de produção dos discursos no/dadas pelo Facebook, consideramos neste item as restrições que reúnem um conjunto de textos publicados por seus "usuários", a partir dos quais fizemos um recorte para a constituição do corpus discursivo, tendo como mecanismo o uso do recurso hashtag.

Para Dias e Coelho (2014,p. 235), tecnicamente, a formulação das hashtags age como hiperlink de assuntos dentro da rede, indexados pelos mecanismos de busca, tais como o Google, e permitem acesso a todas às mensagens, fotos e publicações vinculadas à discussão de um tópico nas redes sociais. Discursivamente, as hashtags marcam um funcionamento; marcam a quantidade a partir da colaboratividade da rede, inscrevendo-se na memória metálica para significar. Acerca da atualização da censura no Facebook, a seleção do corpus foi feita entre março e abril de 2017, a partir das compilações de 2 hashtags representadas por recortes representativos: \#censura \#censuranoFacebook. Pode-se, assim, compreender o discurso por meio da relação entre paráfrase e polissemia, ou seja, entre o "mesmo" e o "diferente", considerando as possibilidades de deslocamento e diferentes efeitos de sentido. Dito isso, assumimos que há saberes sobre censura que falam antes, a memória discursiva (ORLANDI, 1999) que torna possível todo dizer, a condição básica de constituição dos efeitos de sentido. Não obstante, buscamos compreender o modo 
como a censura é discursivizada na atualidade e no Facebook, e as redes de sentido que a ela se filiam.

A ligação entre a materialidade do texto e a sua memória impõe diferentes gestos de interpretação. Especificamente nesta análise, consideram-se que a intersecção entre as materialidades linguística e imagética se impõem na definição do recorte significante da memória. Esse gesto de interpretação segue a linha de Lagazzi (2009) e orienta-nos quanto à análise do objeto simbólico:

O batimento estrutura-acontecimento referido a um objeto simbólico materialmente heterogêneo requer que a compreensão do acontecimento discursivo seja buscada a partir das estruturas materiais distintas em composição. Realço o termo composição para distingui-lo de complementaridade. Não temos materialidades que se complementam, mas se relacionam pela contradição, cada uma fazendo trabalhar a incompletude da outra. Ou seja, a imbricação material se dá pela incompletude constitutiva da linguagem, em suas diferentes formas materiais. $\mathrm{Na}$ remissão de uma materialidade a outra, a não-saturação funcionando na interpretação, permite que novos sentidos sejam reclamados, num movimento de constante demanda (LAGAZZI, 2009 p. 69).

Todos os recortes selecionados são, ou eram no momento da seleção, de acesso público. A fonte de cada matéria está apresentada através da inicial do nome de perfil do usuário ou página e data de publicação.

\section{A- \#CENSURA}

\section{RECORTE 1a: Ed. Humanas (01/03/2017)}

Olá amigxs!

Acho que já todo mundo sabendo do caso com a comissão dos direitos humanos da $O A B-S P$, não quero me estender no assunto já que está tudo na mão dos advogados. Mas eu devo explicação a todos que me seguem desde o início, entre algumas mídias que me procuraram pra falar sobre o caso, escolhi a Dex Magazine pra falar sobre o ocorrido:

Dex Entrevista: Editora Humanas e a censura imposta pela OAB-SP-Dex-Mag No dia 17 de fevereiro a Comissão de Direitos Humanos da OAB-SP soltou uma nota nada democrática e impôs uma espécie de censura contra a página.

Parte inferior do formulário

(Fonte: Facebook. Disponível em:

$<$ https://www.facebook.com/editorahumanas/posts/388463468183931>. Acesso

em: maio 2017) 


\section{RECORTE 1b:}

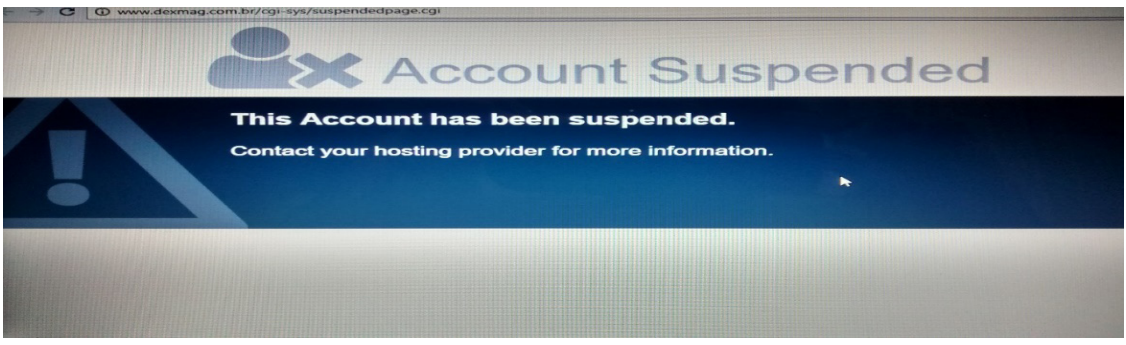

(Fonte: Facebook. Disponível em: < $\underline{\text { http://www.dexmag.com.br/cgi-sys/suspendedpage.cgi }>\text {. Acesso }}$ em: maio 2017).

Ao se clicar no link disponível no Recorte 1a, que remeteria ao objeto de discussão - a censura à página da Ed. H. - publicado na página da "Dex-Mag", aparece o objeto simbólico constante do Recorte 1b. Compreendemos, assim, um duplo apagamento: não é possível acessar à referida página que "falaria" sobre a censura anunciada no Recorte 1a materializada pelo texto verbal censura imposta e espécie de censura, e que teria sido praticada contra a página da Ed. H. O link http:/www.dexmag.com.br/cgi-sys/suspendedpage.cgi foi acessado no momento de leitura da publicação e sugere a suspensão da conta da Dex-Mag. As sequências verbais censura imposta/espécie de censura (Recorte 1a) e Conta suspensa / Esta conta foi deletada (Recorte $1 b^{16}$ ) estão em relação parafrástica com o texto imagético (Recorte $1 \mathrm{~b}$ ), no qual a imagem de um boneco representando o usuário, "proprietário" da conta, aparece lateralmente cortado pela marca $X$, polissemicamente vinculado ao verbal suspenso, deletado, censura (Recorte 1a). A marca $\mathrm{X}$ é significada em relação à memória discursiva como marca utilizada na prática censória em períodos de censura institucionalizada pelo Estado (Moreira, 2009). Em nova consulta à página, realizada em 18/06/2017, aparece a informação "Não é possível acessar o site". De fato, a página www.dexmag.com.br não está acessível.

\section{RECORTE 2:}

Folha de S. Paulo, 20/04/2016

$\mathrm{Na}$ avaliação do ministro, pessoas que se sentirem ofendidas podem recorrer à justiça para pedir retificação do texto ou direito de resposta, mas não podem requerer exclusão das reportagens.

(FOTO DO MINISTRO) ${ }^{17}$

Retirar matéria jornalística do site será sempre censura, diz Barroso.

\footnotetext{
${ }^{16}$ Tradução nossa.

${ }^{17} \mathrm{Na}$ exposição do Recorte 7 e 8, optamos por retirar as fotos, tendo em vista que não estamos considerando as imagens como objeto de análise.
} 
(Fonte: Facebook. Disponível em: <https://www.facebook.com/folhadesp/ posts/1333304953378171>. Acesso em: maio 2017.

\section{RECORTE 3}

Folha de S.Paulo, 1 de junho de 2016

ABI emitiu nota contra a decisão da Justiça do Paraná (via Folha Poder)

Folha

FOTO DO JUIZ SÉRGIO MORO

Tirar do ar textos sobre a Lava Jato é censura, diz Associação Brasileira de Imprensa.

(Fonte: Facebook. Disponível em: $<$ https://www.facebook.com/folhadesp/ posts/1366811260027540>. Acesso em maio 2017.

As sequências linguísticas dos recortes 2 e 3 estão inscritas em duas matérias da página da Folha de S. Paulo no Facebook. As condições de produção referemse à crítica que o Jornal está fazendo sobre a (re)tirada e exclusão, do site, de textos jornalísticos. Nas duas sequências, que estão em relação parafrástica, construindo sentidos sobre as ações praticadas, são citados dois discursos de autoridade - ABI e Ministro Barroso, um dos ministros de maior reconhecimento público no Brasil - para legitimar os efeitos de sentido aí produzidos acerca da censura. Desse modo, a marca linguístico-discursiva é (Recorte 3) e a marca será sempre, através dos verbos de definição "ser" identificam as ações como Censura (Recorte 2 e 3). As marcas tirar e exclusão, em referência ao lugar onde se dá o acontecimento histórico Censura, quer seja no site, indicam uma atualização quanto ao modo e lugar de exercê-la e, ao mesmo tempo em que ele, o verbete site, significa enquanto atualização tecnológica do suporte jornal; uma atualização "no" discurso jornalístico.

B - \#CENSURANOFACEBOOK

RECORTE 4: (L.B, 24/10/2013)

URGENTE, Compartilhem!

Novamente tentam exilar nosso líder, me digam porque tentam nos calar?

A página Brizola Comenta está impedida de postar qualquer conteúdo. 


\section{BRIZOLA GOMENTA BLOQUEADA!}

Este recurso esta temporariamente bloqueado

You recently posted something that viobtes Facebook policies, so you're temoorarly blocked from using this feature. For more information, visic the Helo Center.

To keep from getting blocked again, please make sure you've read and understand Facebook's communcy Standards.

Se você acha que está vendo isso por engano, avise-nos.

Cancelar

FILHOTES DA DITADURA NO FAREBDOK! GOMPREENDEUP!

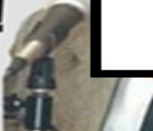

(Fonte: Facebook. Disponivel em: < https://www.facebook.com/BrizolaEterno/photos $>$. Acesso em 12 abril 2016)

A partir da hashtag \#CENSURANOFACEBOOK, compreendemos que há sentidos sendo construídos sobre uma censura que é exercida "no" Facebook. Dáse, assim, ênfase ao modo como esta rede social tomaria uma direção contrária ao que normalmente é naturalizado. Enquanto potencial instrumento de inclusão digital, normalmente relacionadas à ideia de acesso, da facilidade de poder estar neste lugar de dizer através da criação de um perfil, redes sociais como o Facebook criam a ilusão de que "todos" podem dizer "qualquer coisa". É preciso submeter, ao gesto de interpretação, as condições de produção do dizer, ou seja, a página bloqueada, impedida, é a "Brizola Comenta". Leonel Brizola foi um dos políticos mais engajados em posição de resistência à Ditadura Civil-Militar no Brasil e líder do Partido Comunista Brasileiro. É desse lugar histórico, que fala antes, que se reconhece Brizola como líder, e é o "Facebook" o lugar - atualizado - que "usuários" se dizem calados e censurados. Assim, na sequência A página Brizola Comenta está impedida de postar qualquer conteúdo se produz por uma ilusão de que o Facebook seria um espaço livre de dizer ou, de forma atualizada, de postar qualquer coisa. Os sentidos, assim, não são produzidos fora de um lugar de controle, pois a disputa é, também, por um lugar de dizer.

Tanto na sequência linguística de abertura do Recorte 4, quanto na que constitui o objeto simbólico ${ }^{18}$ (Recorte 4), comparecem marcas linguísticodiscursivas que estão em relação parafrástica - ou se repetem - às já apontadas anteriormente nos recortes da hashtag \#Censura. Assim, exilar, impedida, bloqueada e calar são os efeitos de uma prática que já significa, especialmente

\footnotetext{
${ }^{18}$ No lugar da foto de Leonel Brizola optamos por constar apenas a indicação de seu nome.
} 
em períodos ditatoriais, como o que ocorreu, no Brasil, durante a "Ditadura". A marca linguística Filhotes da Ditadura é um modo de fazer a censura atualizada significar a partir de um acontecimento histórico - e discursivo (Moreira, 2009) de vasto conhecimento público dos brasileiros, apontando, portanto, uma direção para os sentidos aí construídos: a censura exercida no Facebook pelos filhotes da Ditadura no Brasil. Quem exerce essa prática agiria, assim, como os que exerceram a censura na Ditadura.

\section{RECORTE 5: (G.F., 24/02/2014)}

Olá pessoas, o Uirá avisa - a quem precisar falar com ele - que está no Telegram. Porque, por aqui, ele foi bloqueado misteriosamente!

\#censuranoFacebook?!?!?!

(Fonte: Facebook. Disponível em :

$<$ https://www.facebook.com/photo.php?fbid=10201632864567377\&set=a.17482

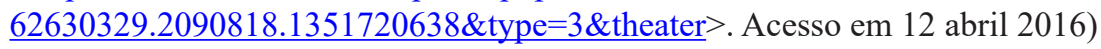

RECORTE 6: (O.G., 12/12/2015)

Perfil anti-Dilma ficou por quatro horas fora do ar, na tarde deste sábado [...]

Vem para Rua classifica como censura página que saiu do ar.

(Fonte: Facebook. Disponível em:

$<$ https://www.facebook.com/jornaloglobo/posts/1170189863020691>. Acesso em 12 abril 2016)

Nas sequências linguísticas dos Recortes 5 e 6, as marcas linguísticodiscursivas bloqueado e saiu do ar vão naturalizando sentidos sobre a prática censória exercida no "Facebook". Algo que precisa ser tomado especialmente em reflexão é o que diz respeito à disputa por um lugar de dizer, ou seja, o que é bloqueado (Recorte 5), o que sai do ar (Recorte 6) e está fora do ar (Recorte 6) vai conseguir dizer, de um outro lugar: no Telegram. É lá que os sentidos possíveis de serem construídos podem significar. Em relação parafrástica com página (Recorte 1a, Recorte 4), as marcas Ele (Recorte 5) e Perfil representam esses sujeitos que estão impedidos, bloqueados, suspensos, exilados. A prática censória, portanto, atua tanto no impedimento da produção e circulação de certos sentidos, quanto na exclusão do próprio sujeito. Assim, está sempre em questão, no campo do discurso, quem pode dizer o quê, como já analisado no Recorte 4. 


\section{CONSIDERAÇÕES FINAIS}

O primeiro aspecto que destacamos com esta análise é quanto à historicidade do verbete "censura"; como ela se discursiviza na atualidade, e de um modo diferente, outro, se retomarmos os estudos acerca da Ditadura Civil-Militar. Em especial, como ela se discursiviza no meio digital e mais especificamente no Brasil.

As práticas de apagamento constituem gestos de constituição de uma memória metálica no Facebook, que possui um modo particular de produção e circulação de sentidos. Essa memória se constitui, por um construto técnico a partir da dispersão próprio sujeito e dos sentidos; ao compartilhar seu dizer, o sujeito do discurso textualizado na materialidade digital não se deixa apagar. Mais: em um gesto discursivo de resistência, e pelo fio da memória, repete - Censura - e atualiza, reconhecendo novos modos de praticá-la. Para resistir, é preciso "compartilhar" o dizer; naturalizar o dito: "Censura". Assim, a "Censura" vai se naturalizando e se atualizando a cada gesto que aponta para o silenciamento. Dessa posição, o sujeito naturaliza o dizer Censura e a ela resiste.

Está sob discussão uma memória que reclama sentidos e uma falta que produz evidências sobre a origem desse dizer, como nos recortes (Recorte 1b) em que o usuário foi removido. Mesmo no funcionamento dos arquivos de censura é possível recuperar saberes que chegam a se inscrever em uma rede de memória. Essa afirmação é importante para compreendermos os efeitos de sentido sobre censura nos discursos desses sujeitos que se filiam a uma posição ideológica ao reconhecerem práticas censórias - algo que se repete - e materializá-las através da marca "x", um saber censório que funciona no Facebook e significa pela memória.

É necessário acentuar que essa censura que está sendo discursivizada se dá por novos gestos, por um modo atualizado de exercer uma prática - no Facebookque já significa na história. Um novo saber atualiza, assim, os sentidos da Censura. Nestes termos, bloquear, suspender, tirar do ar, excluir, exilar, impedir, calar - constituem uma rede de sentidos que retomam os efeitos de sentido da prática censória e, ao mesmo tempo, atualizam-na. A a designação do verbete "censura", por assim significar, é outra, mas o gesto censório, mesmo atualizado pelo recurso tecnológico do Facebook, se filia a um mesmo domínio de memória da censura institucionalizada em 1968; pela negação em lista de proibições (CP3).

A censura discursivizada no Facebook incide não só no discurso "conteúdos", "informações", "páginas" -, mas silencia sujeitos e sentidos. E é justamente nessas condições que o sujeito censurado - suspenso, fora do ar, exilado, impedido, bloqueado, - é lembrado no discurso do Facebook, já que fica proibido de fazer outro perfil usando a mesma identidade. Mas quem censura? Quem e como é possível, a partir dos recortes analisados do Facebook, "apagar", "bloquear", "tirar do ar", "cortar"? Por ora, entendemos que o Facebook é esse outro em relação $a$, que legitima e deslegitima o sujeito e o impede de dizer, de significar(se). Compreendemos que nos Termos de uso e Princípios do Facebook $(T P F)$ são instituídas condições de produção específicas para este construto técnico que regula quem diz o quê. 
Neste percurso de pesquisas, acredito ser importante que, em nossa tomada de posição teórica, continuemos a problematizar, principalmente, a divisão dos sentidos de censura, em especial a partir do que ainda está dado a conhecer das relações de poder entre sujeito, tecnologia e empresas como o Facebook, a maior rede social de disputa pelos sentidos.

\section{REFERÊNCIAS}

ABRAJI - Associação Brasileira de Jornalismo Investigativo (Portal). Projeto Experimental CTRL $+X$ Disponível em: $<$ http://www.ctrlx.org.br/\#/infografico $>$. Acesso em: 15 nov. 2016.

BRASIL. Lei 12.965/14, de 23 de abril de 2014. Estabelece princípios, garantias, direitos e deveres para o uso da Internet no Brasil. Disponível em: $<$ http://www.planalto.gov.br/ccivil_03/_ato20112014/2014/lei/112965.htm>. Acesso em: 15 fev. 2016.

DELEUZE, Gilles, Desejo e prazer. In: PELBART, Peter; ROLNIK, Suely (Orgs.). Cadernos de subjetividade. São Paulo: PUC-SP, v. 1, n. 1, 1993.

DIAS, Cristiane. Memória Metálica (Verbete). Enciclopédia discursiva da cidade. Disponível em: $<$ http://www.labeurb.unicamp.br/endici/index.php? $\mathrm{r}=$ verbete/view\&id=119>. Acesso em: 12 maio 2016.

DIAS, Cristiane. Espaço, tecnologia e informação: uma leitura da cidade. In: RODRIGUES, Eduardo. A.; SANTOS, Gabriel. L. dos; BRANCO, Luiza. K. C.(Orgs.). Análise de discurso no Brasil: pensando o impensado sempre: uma homenagem a Eni Orlandi. Campinas: RG, 2011a. p. 259272.

DIAS, Cristiane; COELHO, André. V de vinagre: a produção de imagens humorísticas sobre as manifestações brasileiras de 2013 nas redes sociais. In. PATTI, Ane Ribeiro et. al. (orgs.) Textecendo discursos na contemporaneidade. São Carlos: Pedro \& João Editores, 2012. Acesso em: 12 maio 2016.

FACEBOOK . Página inicial. 2017. Disponível em: <www.facebook.com> Acesso em: 03 fev. 2016.

FACEBOOK. Termos e Políticas do Facebook. Disponível em: $<\underline{\text { https://pt-br.Facebook .com/policies }>}$ Acesso em: 06 abr. 2017.

FOUCAULT, Michel. Estratégia, Poder-Saber. Trad. Vera Lúcia Avellar Ribeiro. 2 ed. Rio de Janeiro: Forense Universitária, 2006.

FOUCAULT, Michel. Microfisica do Poder. Trad. Roberto Machado. 20 ed. Rio de Janeiro: Edições Graal, 1999a.

FOUCAULT, Michel. Em defesa da Sociedade. Curso no Collège de France (1975-1976). Trad. Maria Ermantina Galvão. São Paulo: Martins Fontes, 1999b. 
KANASCHIRO, Marta. Vigiar e resistir: a constituição de práticas e saberes em torno da informação. Ciência e Cultura, Campinas, v. 68, n. 1, p. 20-24, 2016. Disponível em $<$ http://cienciaecultura. bvs.br/pdf/cic/v68n1/v68n1a10.pdf > . Acesso em: 25 maio 2017.

LAGAZZI, Suzy. O recorte significante da memória. In: INDURSKY, F; FERREIRA, M. C; MITTMAN, S. (Orgs.). O discurso na contemporaneidade: materialidades e fronteiras. São Carlos: Claraluz, 2009.

MARIANI, Bethania. Subjetividade e Imaginário Linguístico. Linguagem em (Dis)curso, Tubarão, v. 3, Número Especial, p. 55-72, 2003.

MARIANI, Bethania. Colonização lingüistica: língua, política e religião no Brasil (séculos XVI a XVIII) e nos Estados Unidos da América (século XVIII). São Paulo: Pontes, 2004.

MOREIRA, Carla. Censura e silenciamento no discurso jornalístico. In: RIBEIRO, Ana Paula; FERREIRA, Lucia Maria (Orgs.). Mídia e memória: a produção de sentidos nos meios de comunicação. Rio de Janeiro: Mauad X, 2007. p. 319-342.

MOREIRA, Carla. Produção, circulação e funcionamento da censura na ditadura militar brasileira e no fascismo italiano: a censura na ordem do discurso. Tese (Doutorado). Universidade Federal Fluminense, Instituto de Letras, 2009. 187p.

MOREIRA, Carla. Censura, memória e arquivo discursivo. In: Veredas on line - Análise do Discurso. Juiz de Fora, n. 2, p. 107-118, 2010. Disponível em $<$ http://www.ufjf.br/revistaveredas/ files/2010/04/artigo-08.pdf $>$. Acesso em: 10 de abril de 2016.

ORWELL, George. 1984. São Paulo: Companhia das Letras, 2010.

ORLANDI, Eni. As formas do silêncio: no movimento dos sentidos. 5 ed. SP: Ed. Unicamp. 2007[1992].

ORLANDI, Eni. Análise do Discurso: Princípios e Procedimentos. 5.ed. São Paulo: Ed. Pontes, 2003[1999].

ORLANDI, Eni. Os recursos do Futuro: Um outro discurso. Multiciência, Campinas, n.1, p. 1-7. 2003. Disponível em: <https://www.multiciencia.unicamp.br/artigos_01/A5 Orlandi port.PDF>. Acesso 10 jun. de 2016.

ORLANDI, Eni. Interpretação: autoria, leitura e efeitos do trabalho simbólico. Campinas: Pontes, 2004[1996]).

ORLANDI, Eni. Análise do Discurso: conversa com Eni Orlandi. In: Goulart, Raque. Teias: Rio de Janeiro, ano 7, n. 13-14, jan/dez 2006 (Entrevista).

ORLANDI, Eni. Tecnologias da linguagem: um novo funcionamento. In: O que é linguística. São Paulo: Brasiliense, 2009.

ORLANDI, Eni. A contrapelo: incursão teórica na tecnologia: discurso eletrônico, escola, cidade. Rua [online], n. 16, v. 2, Campinas, Labeurb/Unicamp, 2010. Disponível em $<$ http://www.labeurb. unicamp.br/rua/pages/pdf/16-2/1-16-2.pdf $>$. Acesso em 5 mar.2016. 
ORLANDI, Eni. A materialidade do gesto de interpretação e o discurso eletrônico. In: DIAS, C. (Org.). Formas de mobilidade no espaço e-urbano: sentido e materialidade digital. Campinas: Labeurb/ Nudecri, 2013.

PÊCHEUX, Michel. Semântica e Discurso: uma crítica à afirmação do óbvio. Tradução de Eni P. Orlandi et al. Campinas, SP: Editora da UNICAMP, 1988[1975].

THOMPSON, JohnB. The new visibility. Theory. In: Culture \& Society, n²2, 2005. 